\title{
Valproic acid as an anticancer therapy-sensitizing agent
}

Gabriela Rebeca Luna-Palencia, ${ }^{1}$ José Correa-Basurto² and Ismael Vásquez-Moctezuma ${ }^{3 *}$

${ }^{1}$ Centro de Investigación y de Estudios Avanzados, Instituto Politécnico Nacional, Department of Biotechnology; ${ }^{2}$ Instituto Politécnico Nacional, Higher School of Medicine, Postgraduate Studies and Research Section, Laboratory of Molecular Modeling and Drug Design; ${ }^{3} I n s t i t u t o ~ P o l i t e ́ c h i c o$ Nacional, Higher School of Medicine, Postgraduate Studies and Research Section. Mexico City, Mexico

\begin{abstract}
Valproic acid is an antiepileptic drug with more than 50 years of clinical use. In the past decade, its anticancer effects were discovered. Analyses in groups of patients who used this drug for years have shown that it decreases the frequency of head and neck cancer. Recent studies show the anticancer effect of combining valproic acid with chemotherapy, biological therapy and antioxidant systems inhibitors, with exceptional results. In this review, we analyze the metabolism of valproic acid and its application against cancer.

KEY WORDS: Valproic acid. Human cancer therapy. Epigenetic therapy. Histone deacetylase inhibitors.
\end{abstract}

\section{Introduction}

Valproic acid (VPA) is used in neurological diseases such as epilepsy, migraine, bipolar disorder and attention deficit. ${ }^{1,2}$ VPA functions as a sensitizer to anticancer treatments by epigenetically modifying gene expression.

\section{Epigenetics and cancer}

Malignant neoplasms lose the ability to control their proliferation, invading other tissues (metastasis). ${ }^{3}$ This alteration is due to mutations in proto-oncogenes and tumor-suppressor genes. The above is generated by genetic and epigenetic changes. ${ }^{3,4}$ Epigenetic changes can be reversible and consist of mechanisms such as methylation of DNA cytokine-rich regions $(\mathrm{CpG})$ or "CpG islands" that when methylated inhibit gene expression, messenger RNA block by micro-RNA molecules (miRNA) and histone deacetylation. ${ }^{3,4}$

\section{Histone deacetylases and acetyltransferases in the epigenetic control of genes}

DNA is wrapped around histone octamers $\left(\mathrm{H}_{2} \mathrm{~A}\right.$, $\mathrm{H} 2 \mathrm{~B}, \mathrm{H} 3$ and $\mathrm{H} 4$ ) that form the nucleosome, which when condensed integrate chromatin. ${ }^{5}$ Each histone has a "tail" in the amino terminus, which is rich in basic amino acids such as lysine, a post-translational modification target, thus making for accessibility, to DNA to be partially controlled by changes in this structure. ${ }^{6}$ Histones regulatory mechanisms include modifications by methylation, acetylation, phosphorylation and ubiquitination, among others. ${ }^{7}$ Acetylation and deacetylation of histones and cytoplasmic proteinsare
Correspondence:

*Ismael Vásquez Moctezuma

E-mail: g17isma65@gmail.com
Date of reception: 15-10-2018

Date of acceptance: 29-10-2018

DOI: 10.24875/GMM.M19000307
Gac Med Mex. 2019;155:384³88

Contents available at PubMed www.gacetamedicademexice.com 


\begin{tabular}{|c|c|c|c|}
\hline HDAC Group & HDAC Enzyme & Proteins it interacts with & $\simeq$ \\
\hline \multirow[t]{4}{*}{ Class I (homologous to Rpd3) } & HDAC1, HDAC2, HDAC3, HDAC8 & $\begin{array}{l}\text { p53, RB, MYOD, NF-кB, DNMT1, DNMT3a, MBD2, Sp1, BF } \\
\text { MeCP2, ATM, Smad7 }\end{array}$ & $\operatorname{RCAT}$ \\
\hline & HDAC2 & RB, NF-кB , BRCA1, DNMT1 & 0 \\
\hline & HDAC3 & RB, NF-кB , Smad7, Stat3, SRY & (2) \\
\hline & HDAC8 & ND & $\frac{1}{1}$ \\
\hline \multirow[t]{4}{*}{ Class IIla (homologous to Hdac) } & HDAC4 & MEF2 & $\underline{n}$ \\
\hline & HDAC5 & MEF2 & 르 \\
\hline & HDAC7 & MEF2 & $\stackrel{0}{\rightleftharpoons}$ \\
\hline & HDAC9 & & 4 \\
\hline \multirow[t]{2}{*}{ Class IIb } & HDAC6 & Smad7, $\alpha$-tubulin, Hsp-90 & 으 \\
\hline & HDAC10 & & $\cdot \frac{n}{\varepsilon}$ \\
\hline \multirow[t]{7}{*}{ Class III (homologous to Sir2) } & SIRT1 & p53, FOX01, p300, NF-кB, $\alpha$-tubulin & อั \\
\hline & SIRT2 & $\alpha$-tubulin & $\frac{c}{d}$ \\
\hline & SIRT3 & & $\frac{2}{y}$ \\
\hline & SIRT4 & & ฮั \\
\hline & SIRT5 & & 으 \\
\hline & SIRT6 & Heterochromatin-related & $\stackrel{\Perp}{\rightleftarrows}$ \\
\hline & SIRT7 & Nucleolus-related & ว \\
\hline Class IV(similar to classes I and II) & HDAC11 & & 昰 \\
\hline
\end{tabular}

reversible and are controlled by two enzymes: histone acetyltransferases and histone deacetylases (HDAC). ${ }^{8}$ Histone acetyltransferases transfer acetyls to histone tails' lysine, which eliminates lysine positive charge, thus decreasing binding with DNA. As a consequence, transcription factors and RNA polymerase do access. $^{7,8}$ Conversely, HDACs remove acetyl groups, thus increasing DNA attraction towards positive histone charges; this compacted DNA does not allow the entry of transcription factors or RNA polymerase. In cancer, suppressor genes are preferably deacetylat$\mathrm{ed}^{7,8}$. Acetylation also controls cytoplasmic proteins, regulating gene expression, cell cycle, splicing, transport and actin nucleation. ${ }^{9}$

\section{The HDAC family}

In humans, 11 HDACs are known, divided into classes I, II, III and IV, whose classification is based on their homology with yeast HDACs: ${ }^{6}$

- Class I HDAC, proteins that use $\mathrm{Zn}^{+}$as cofactor and express themselves ubiquitously and include HDAC1, HDAC2, HDAC3 and HDAC8.
- Class Ila HDACs include HDAC4, HDAC5, HDAC7 and HDAC9; they are found both in the nucleus and the cytoplasm,

- Class IIb HDACs are present in the cytoplasm and include HDAC6 and HDAC10.

- Class III HDACs, sirtuins, are located in the cytoplasm and mitochondria; they use nicotinamide and adenine dinucleotide as cofactors.

- Class IV HDACs include HDAC11 and are located in the cytoplasm ${ }^{10,11}$ (Table 1).

HDAC1, HDAC2, HDAC3 and HDAC8 participate in cell proliferation. In apoptosis, HDAC1 and HDAC2 stand out. In chemotherapy resistance, HDAC1 predominates; in differentiation, HDAC3, HDAC4, HDÁC5 and HDAC8; in angiogenesis, HDAC4, HDAC6, HDAC7 and HDAC10; and in migration, HDAC6.

\section{Valproic acid metabolism}

VPA in children has been associated with liver'failure. ${ }^{14-16}$ Its elimination depends on its biotransformation into more water-soluble products, a process that is divided in two phases: ${ }^{14}$ 

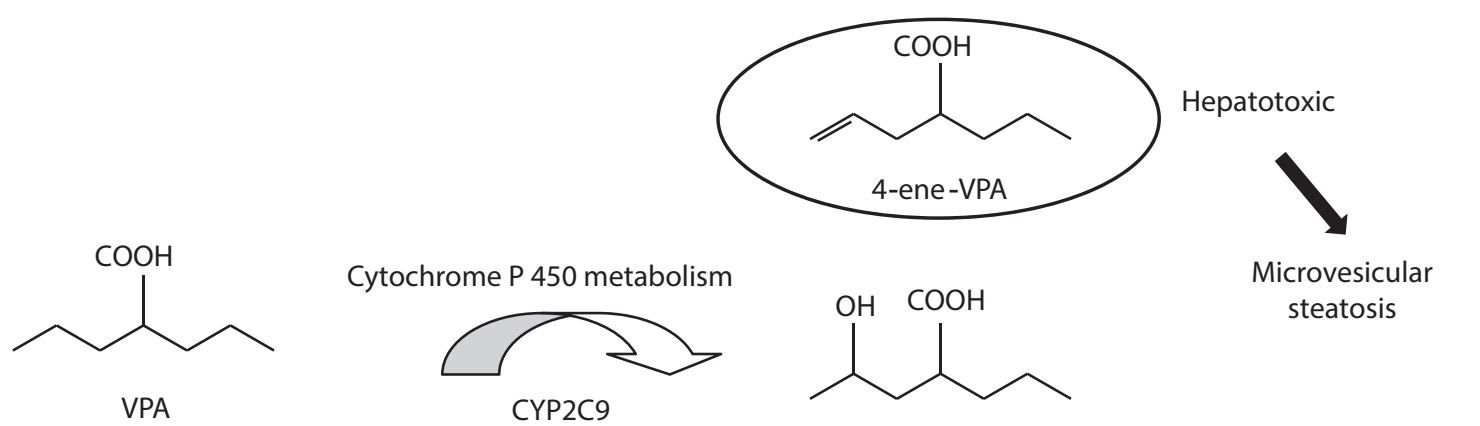

CYP2C9

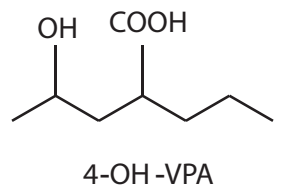

Microvesicular steatosis

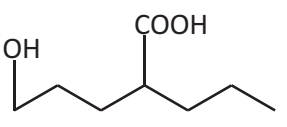

5-OH-VPA

Figure 1. Valproic acid biotransformation by the cytochrome system; hepatotoxic 4-ene-valproic metabolite formation is shown.

- Phase I, includes oxidation, reduction and hydrolysis reactions.

- Phase II, where conjugation reactions with glucuronate, glutathione, carnitine, coenzyme A or with amino acids such as glycine or glutamic acid do participate.

VPA oxidative metabolism is mitochondrial by means of beta oxidation. In hepatocytes, it is inactivated by phase II, which by conjugation generates renal excretion polar products. VPA is a substrate for the CYP2C6 and CYP2C9 isoforms. ${ }^{17,18}$ Of all the metabolism compounds that are generated, 4-ene-valproic is more hepatotoxic (Fig. 1). ${ }^{16}$

\section{HDAC-inhibitors mechanism of action}

HDAC inhibitors (HDACis), such as VPA, stop the cell cycle, generate differentiation and apoptosis in human cancer cell lines, inhibit tumor growth in animal models and have shown antitumor activity in controlled clinical trials. ${ }^{19-21}$ In addition, they activate autophagy, generate reactive oxygen species and disrupt the agressome pathway. ${ }^{13}$ HDAC inhibition causes over-acetylation of these proteins, which reactivates the transcription of tumor suppressor genes and reverts cancer. ${ }^{6}$

In controlled clinical trials, HDACis show acceptable results in the treatment of hematological neoplasms and, therefore, in 2006, the Food and Drug Administration approved the suberanilohydroxamic acid (SAHA, vorinostat) and, in 2009, romidepsin, for the treatment of T-cell cutaneous lymphoma, bone marrow dysplasia and peripheral T-cell lymphoma. ${ }^{22}$ In early 2015, panobinostat was approved for the managent of multiple myeloma. ${ }^{23}$ Notwithstanding the above, the results in solid tumors have been variable. ${ }^{24} \mathrm{HDAC}$ is could also be useful in viral diseases and diabetes mellitus ${ }^{2,23-27}$ Good results have been observed infollicular lymphoma and marginal zone lymphoma. ${ }^{28}$ o

Originally, VPA was observed to inhibit murine heuroblastoma and glioma cell proliferation; continüed exposure to VPA has also been found to induce cell lines differentiation and apoptosis. ${ }^{29-32}$ VPA has been classified as a selective class I HDAC inhibitor. ${ }^{24}$

\section{VPA in silico modeling on HDAC8}

The mechanism whereby VPA inhibits HDACs is not known; however, an in silico study with HDAC8 using VPA as a ligand suggests that there are two binding sites: the catalytic site and the hydrophobic channel of the active site. VPA's carboxyl group interacts with the catalytic site. On the other hand, acetate is thought to be released into the hydrophobic channel of the active site, thus blocking the enzyme. ${ }^{34}$

\section{VPA sensitizes cancer and helps chemotherapy}

In cancer therapy, VPA has been applied as mönotherapy or in combination with demethylating epigenetic agents, chemotherapy and immune system modulators ${ }^{35}$ 
In a phase II investigation, VPA monotherapy was observed to be able to induce the expression of Notch I (a tumor suppressor) in neuroendocrine carcinoma; the study included eight patients, out of which one did partially respond and five evolved to stable disease. ${ }^{36}$ In vitro, in myeloid neoplasms, VPA has shown apoptosis and differentiation induction in non-differentiated leukemic cells, which has stimulated the use of VPA as monotherapy or in combination with all-trans retinoic acid in acute myeloid leukemia (AML) and myelodysplastic syndrome (MDS). In a phase II study with $75 \mathrm{pa}$ tients treated with VPA associated with all-trans retinoic acid, 18 patients (24\%) were reported to have achieved adequate responses. In another study with VPA and all-trans retinoic acid, 20 patients with MDS were treated: clinical benefit was observed in $30 \%$ of patients with AML and MDS. ${ }^{37,38}$ In another approach, 5-azacitidine plus VPA was used, with better response than with conventional therapy being reported in phase I, II and III trials in older adults with AML and MDS. ${ }^{37,39,40}$ In a phase II trial of VPA with all-trans retinoic acid and 5-azacitidine applied to patients with AML and with lowrisk MDS, responses were observed in $23 \%$ of patients and a 12.4-month survival. ${ }^{41}$

Combinations of VPA with chemotherapy include agents that damage the DNA. In a study where it was combined with epirubicin (topoisomerase II inhibitor), responses were observed in $22 \%$ of the 44 patients included, among them patients with tumors regarded as anthracycline-resistant, such as melanomas..$^{42}$ In a phase I-II trial, VPA was combined with 5-fluorouracil, epirubicin and cyclophosphamide in a cohort of 15 breast cancer patients; acceptable toxicity was observed in $64 \%$ of patients. ${ }^{35}$ In a phase II clinical trial of 16 patients with cisplatin-resistant inoperable malignant mesothelioma, synergistic results were detected with the combination of VPA and doxorubicin; seven patients out of 45 showed partial responses. ${ }^{43}$ In another phase I/II clinical trial of patients with metastatic melanoma, VPA was used in combination with karenitecin, a topoisomerase I inhibitor; the result was disease stabilization in $47 \%$ (seven out of 15 patients in the dose escalation cohort). ${ }^{44}$ In a phase III randomized analysis that included 36 patients with advanced cervical cancer, the hydralazine, VPA, cisplatin and topotecan combination resulted in a significant improvement in progression-free survival. ${ }^{45}$ Other in vitro work showed that VPA increases histone $\mathrm{H} 3$ acetylation. With these histone changes, this drug prevents mTOR inhibition-mediated resistance by the RAD001 compound (everolimus) in renal carcinoma CaKi-1 cells. ${ }^{46}$

\section{VPA to prevent head and neck cancer}

In a retrospective study of a cohort of 439,628 older adults treated with VPA for different diagnoses (bipplar disorder, migraine, epilepsy), a lower frequency of smoking-related head and neck carcinoma wassobserved in 26,911 individuals who chronically used VPA. ${ }^{47}$

Interestingly, in vitro trials of cultures of cancercell lines, in vivo trials with animal models and clinical studies show that VPA decreases the resistance to conventional cancer therapy. ${ }^{45,47}$

\section{Conclusions}

In studies with large patient populations, VPA thas been shown to prevent head and neck cancer; in addition, some clinical trials reveal its usefulness as combination therapy. Recently, the combination of VPA, chemotherapy and agents that block antioxidant systems (glutathione) has been used with interesting results in cancer cell lines. ${ }^{34,48}$

The works using the VPA as a base-molecule for designing new compounds focus on molecules with HDAC inhibition related to cancer with low hepatotoxicity. In this regard, our group has worked with the design and testing of VPA-derived drugs, with $\mathrm{N}-(2 \mathrm{zh} y-$ droxyphenyl)-2-propylpentanamide (O-OH-VPA) standing out, which has shown its antiproliferative effect in Hela, sarcoma and MCF7 cell cultures. ${ }^{4}$

\section{Funding}

Gabriela Luna Palencia is Conacyt (grant 91136)and Secretaría de Investigación y Posgrado del Instifuto Politécnico Nacional (project 20151399).

\section{Conflict of interests}

The authors declare that there were no conflicts of interests that might have affected the execution of this work.

\section{References}

1. Frazee LA, Foraker KC. Use of intravenous valproic acid for acute migraine. Ann Pharmacother. 2008;42:403-407.

2. Rosenberg $\mathrm{G}$. The mechanisms of action of valproate in neuropsychiatric disorders: can we see the forest for the trees? Cell Mol Life Sci.(2007; 64:2090-2103

3. Hanahan D, Weinberg RA. Hallmarks of cancer: the next generation. Cell. 2011:144:646-674.

4. Dawson MA, Kouzarides T. Cancer epigenetics: from mechanism to therapy. Cell. 2012;150:12-27. 
5. Tessarz $P$, Kouzarides $T$. Histone core modifications regulating nucleosome structure and dynamics. Nat Rev Mol Cell Biol. 2014;15:703-708.

6. Robey RW, Chakraborty AR, Basseville A, Luchenko V, Bahr J, Zhirong Zhan Z, et al. Histone deacetylase inhibitors: emerging mechanisms of resistance. Mol Pharm. 2011:8:2021-2031.

7. Dawson MA, Kouzarides T. Cancer epigenetics: from mechanism to therapy. Cell. 2012;150:12-27.

8. Seto E, Yoshida M. Erasers of histone acetylation: the histone deacetylase enzymes. Cold Spring Harb Perspect Biol. 2014;6:a018713.

9. Choudhary C, Kumar C, Gnad F, Nielsen ML, Rehman M, Walther TC et al. Lysine acetylation targets protein complexes and co-regulates major cellular functions. Science. 2009:325:834-840.

10. Delcuve GP, Khan DH, Davie JR. Roles of histone deacetylases in epigenetic regulation: emerging paradigms from studies with inhibitors. Clinical Epigenetics. 2012;4:5

11. De-Ruijter AJM, Van-Gennip AH, Caron HN, Kemp S, Van Kuilenburg AB. Histone deacetylases (HDACs): characterization of the classical HDAC family. Biochem. J. 2003;370:737-749.

12. Dejligbjerg M, Grauslund M, Litman T, Collins L, Qian X, Jeffers M, et al. Differential effects of class I isoform histone deacetylase depletion and enzymatic inhibition by belinostat or valproic acid in HeLa cells. Mol Cancer. 2008:7:70.

13. Witt O, Deubzer HE, Lodrini M, Milde T, Oehme I. Targeting histone deacetylases in neuroblastoma. Curr Pharm Des. 2009;15:436-447.

14. Silva MF, Aires CC, Lui PB, Ruiter JP, IJIst L, Durán M, et al. Valproic acid metabolism and its effects on mitochondrial fatty acid oxidation: a review. J Inherit Metab Dis. 2008;31:205-216.

15. Puri AS, Sharma BC, Khan EM, Saraswat VA. Fatal fulminant hepatic failure due to sodium valproate in an adolescent. Indian Pediatr. 1994;31:207-210.

16. Ho PC, Abbott FS, Zanger UM, Chang TK. Influence of CYP2C9 genotypes on the formation of a hepatotoxic metabolite of valproic acid in human liver microsomes. Pharmacogenomics J. 2003:3:335-342.

17. Kiang TK, Ho PC, Anari MR, Tong V, Abbott FS, Chang TK. Contribution of CYP2C9, CYP2A6, and CYP2B6 to valproic acid metabolism in hepatic microsomes from individuals with the CYP2C9*1/*1 genotype. Toxicol Sci. 2006;94:261-271.

18. Sedeque AJM, Fisher MB, Korzekwa KR, González FJ, Rettie AE. Human CYP2C9 and CYP2A6 mediate formation of the hepatotoxin 4-ene-valproic acid. J Pharmacol Exp Ther. 1997;283:698-703.

19. Fantin VR, Richon VM. Mechanisms of resistance to histone deacetylase inhibitors and their therapeutic implications. Clin Cancer Res. 2007; 13:7237-7242.

20. Olsen EA, Kim YH, Kuzel TM, Pacheco TR, Foss FM, Parker S, et al. Phase Ilb multicenter trial of vorinostat in patients with persistent, progressive, or treatment refractory cutaneous T-cell lymphoma. J Clin Oncol. 2007:25:3109-3115

21. Bassett SA, Barnett MP. The role of dietary histone deacetylases (HDACs) inhibitors in health and disease. Nutrients. 2014:6:4273-4301.

22. McGraw AL. Romidepsin for the treatment of T-cell lymphomas. Am J Health Syst Pharm. 2013;70:1115-1122.

23. Garnock-Jones KP. Panobinostat: first global approval. Drugs. 2015 75:695-704.

24. Mercurio C, Minucci S, Pelicci PG. Histone deacetylases and epigenetic therapies of hematological malignancies. Pharmacol Res. 2010;62:18-34.

25. Ghosh SK, Perrine SP, Williams RM, Faller DV. Histone deacetylase inhibitors are potent inducers of gene expression in latent EBV and sensitize lymphoma cells to nucleoside antiviral agents. Blood. 2012;119:1008-1017.

26. Fraga MF, Ballestar E, Villar-Garea A, Boix-Chornet G, Espada J, Schotta G, et al. Loss of acetylation at Lys16 and trimethylation at Lys20 of histone $\mathrm{H} 4$ is a common hallmark of human cancer. Nat Genet. 2005;3:391-400.

27. Thurn KT, Thomas S, Moore A, Munster PN. Rational therapeutic combinations with histone deacetylase inhibitors for the treatment of cancer. Future Oncol. 2011:7:263-283.

28. Kirschbaum MH. Histone deacetylase inhibitors and Hodgkin's lymphoma. Lancet Oncol. 2011;12:1178-1179.

29. Zapotocky M, Mejstrikova E, Smetana K, Stary J, Trka J, Starkova J. Valproic acid triggers differentiation and apoptosis in AML1/ETO-positive leukemic cells specifically. Cancer Lett. 2012;319:144-153.

30. Iacomino G, Medici MC, Russo GL. Valproic acid sensitizes K562 erythroleukemia cells to TRAIL/Apo2L-induced apoptosis. Anticancer Res. 2008;28:855-864.

31. Göttlicher M, Minucci S, Zhu P, Krämer OH, Schimpf A, Giavara S, et al. Valproic acid defines a novel class of HDAC inhibitors inducing differentiation of transformed cells. EMBO J. 2001;20:6969-6978.
32. Phiel CJ, Zhang F, Huang EY, Guenther MG, Lazar MA, Klein PS. Histone deacetylase is a direct target of valproic acid, a potent anticonvulsant, mood stabilizer, and teratogen. J Biol Chem. 2001,276: 36734-36741.

33. Khan N, Jeffers M, Kumar S, Hackett C, Boldog F, Khramtsov N et al. Determination of the class and isoform selectivity of small-mofecule histone deacetylase inhibitors. Biochem J. 2008;409:581-589.

34. Bermúdez-Lugo JA, Perez-Gonzalez $\mathrm{O}$, Rosales-Hernández MC, 而izaliturri-Flores I, Trujillo-Ferrara J, Correa-Basurto J. Exploration of the valproic acid binding site on histone deacetylase 8 using docking and molecular dynamic simulations. J Mol Model. 2012;18:2301-2310?

35. Münster P, Marchion D, Bicaku E, Lacevic M, Kim J, Centeno B, et al. Clinical and biological effects of valproic acid as a histone deacetyllase inhibitor on tumor and surrogate tissues: phase I/II trial of valproic-acid and epirubicin/FEC. Clin Cancer Res. 2009:15:2488-2496.

36. Mohammed TA, Holen KD, Jaskula-Sztul R, Mulkerin DR, Lubner SJ Schelman WR, et al. A pilot phase II study of valproic acid for treatment of low-grade neuroendocrine carcinoma. Oncologist. 2011;16:835-843.

37. Kuendgen A, Knipp S, Fox F, Strupp C, Hildebrandt B, Steidl C,cet al. Results of a phase 2 study of valproic acid alone or in combination with all-trans retinoic acid in 75 patients with myelodysplastic syndrome and relapsed or refractory acute myeloid leukemia. Ann Hematol. 2005; 84:61-66.

38. Pilatrino C, Cilloni D, Messa E, Morotti A, Giugliano E, Pautasso M.cet al. Increase in platelet count in older, poor-risk patients with acute myeloid leukemia or myelodysplastic syndrome treated with valproic acid and all-trans retinoic acid. Cancer. 2005;104:101-109.

39. Fenaux P, Mufti GJ, Hellstrom-Lindberg E, Santini V, Finelli C, Giagounidis $A$, et al. Efficacy of azacitidine compared with that of conventional care regimens in the treatment of higher-risk myelodysplastic syndromes: a randomised, open-label, phase III study. Lancet Oncol..2009; 10:223-232.

40. Fenaux P, Mufti GJ, Hellström-Lindberg E, Santini V, Gatterma⿳亠㐅冋n N, Germing $U$, et al. Azacitidine prolongs overall survival compared with conventional care regimens in elderly patients with low bone marrow blast count acute myeloid leukemia. J Clin Oncol. 2010;28:562-569.

41. Raffoux E, Cras A, Recher C, Boëlle PY, De Labarthe A, Turlure P, et al. Phase 2 clinical trial of 5-azacitidine, valproic acid, and all-trans retinoic acid in patients with high-risk acute myeloid leukemia or myelodysplastic syndrome. Oncotarget. 2010:1:34-42.

42. Münster P, Marchion D, Bicaku E, Schmitt M, Lee JH, DeConti R, et al. Phase I trial of histone deacetylase inhibition by valproic acid followed by the topoisomerase II inhibitor epirubicin in advanced solid tumors: a clinical and translational study. J Clin Oncol. 2007;25:1979-1985.;

43. Scherpereel A, Berghmans T, Lafitte JJ, Colinet B, Richez M, Bonduelle $Y$, et al. Valproate-doxorubicin: promising therapy for progressing mesothelioma. A phase II study. Eur Respir J. 2011;37:129-135. =

44. Daud AI, Dawson J, DeConti RC, Bicaku E, Marchion D, Bastien Scet al. Potentiation of a topoisomerase I inhibitor, karenitecin, by the histone deacetylase inhibitor valproic acid in melanoma: translational and phase I/II clinical trial. Clin Cancer Res. 2009;15:2479-2487.

45. Coronel J, Cetina L, Pacheco I, Trejo-Becerril C, González-Fierro \&, De la Cruz-Hernández E, et al. A double-blind, placebo-controlled, randomized phase III trial of chemotherapy plus epigenetic therapy with hydralazine valproate for advanced cervical cancer. Preliminary results. Med Oncol. 2011;28:S540-S546.

46. Juengel E, Dauselt A, Makarević J, Wiesner C, Tsaur I, Bartsch G, Set al. Acetylation of histone $\mathrm{H} 3$ prevents resistance development caused by chronic mTOR inhibition in renal cell carcinoma cells. Cancer Lett. 2012;324:83-90

47. Kang H, Gillespie TW, Goodman M, Brodie SA, Brandes M, Ribeiro M, et al. Long-term use of valproic acid in US veterans is associated with a reduced risk of smoking-related cases of head and neck cancer. Cancer. 2014:120:1394-1400.

48. Luna-Palencia GR, Martínez-Ramos F, Vásquez-Moctezuma I, Eragoso-Vázquez MJ, Mendieta-Wejebe JE, Padilla-Martínez II, et al. Three amino acid derivatives of valproic acid: design, synthesis, theoretical and experimental evaluation as anticancer agents. Anticancer Agents 5 Med Chem. 2014;14:984-993

49. Prestegui-Martel B, Bermúdez-Lugo JA, Chávez-Blancō $A$ Dueñas-González A, García-Sánchez JR, Pérez-González OA, et al. $\mathrm{N}$-(2-hydroxyphenyl)-2-propylpentanamide, a valproic acid aryl derivative designed in silico with improved anti-proliferative activity in HeLa, thabdomyosarcoma and breast cancer cells. J Enzyme Inhib Med Chem. 2016;31:140-149. 